\title{
LAURENGE-MOON-BIEDL SYNDROME
}

A REPORT OF TWO CASES

By

PAULINE KLENERMAN, LoNdoN

In view of the rarity of the Laurence-Moon-Biedl syndrome I should like to record two cases, both of which present interesting features.

Case I.-E. A. B., female, age 40. Admitted to Leavesden Mental Hospital on August 30, 1922.

Family History.-The parents were not related to each other. A maternal cousin died in Colney Hatch Asylumapart from this the family history was negative. Age of father at patient's birth was 43 ; age of mother, 45. There were three sisters and one step-brother, but in none was evidence of extra fingers or toes obtained.

Personal IIistory.-Her birth was normal. In 1884-85 two supernumerary digits were removed at St. George's Hospital. In 1887 her sight was stated to have become affected.

Present Appearance.-An extremely obese subject: obesity most marked round abdomen and mammæ (fig. 1). Face plump. Patient exhibits constant choreiform movements of the face, as well as rotatory movements of the eyes. Nose is small, lips are not thickened, tongue is moist. Height 5 ft. 1 in., weight 15 st. in 1931,15 st. $3 \mathrm{lb}$. in 1934. Head circumference 21 in.

Heart sounds are distant, with a first mitral impurity; B.P. 135/115. Lungs, negative. Abdomen extremely obese. No splenic or hepatic enlargement.

Eyes : pupils equal, circular, react to light. There is definite nystagmus. Lenticular opacities present. Ophthalmoscopic examination reveals an irregular pigmentation all over the retinæ. The patient is partially blind.

Upper limbs : Right hand possesses six digits with syndactyly of middle and

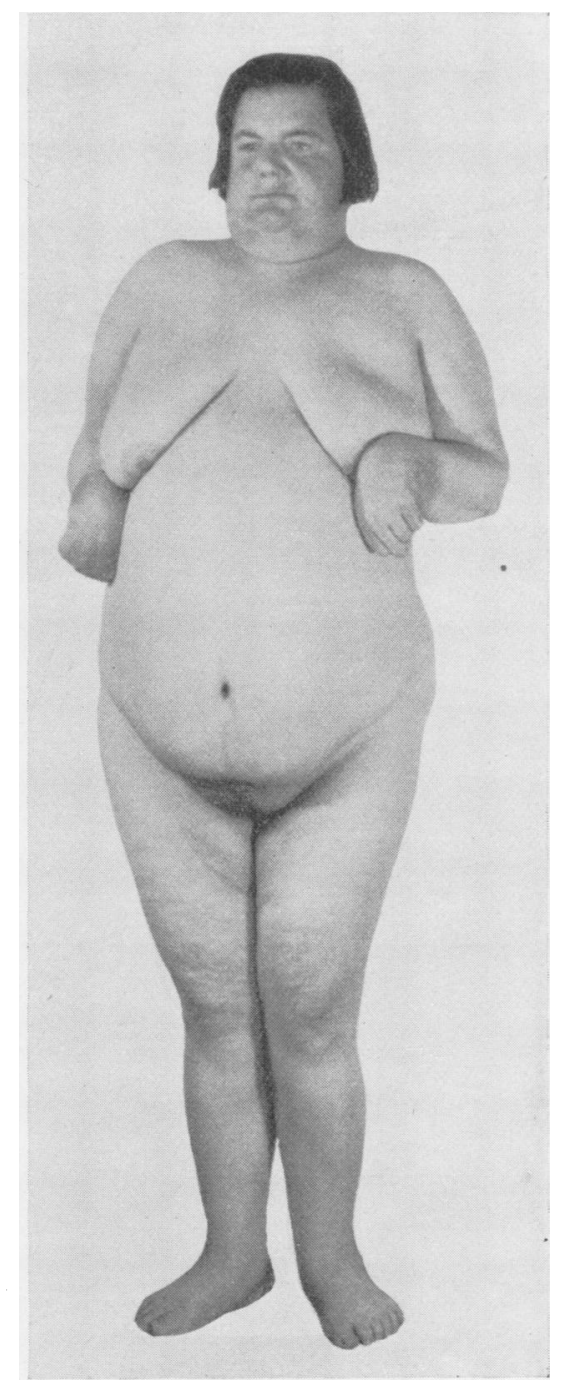

Frg. 1. 
double ring finger (ring finger presents two distinct nails). On the outer side of the hand a small scar is seen, where a supernumerary rudimentary finger was removed some years ago. X-ray film of right hand shows a small spicule of bone about $\frac{1}{8}$ in. long arising from the middle of the fifth metacarpal, and three terminal phalanges for the middle and ring fingers which are fused together (fig. 2). Left hand : Five digits with a scar of a rudimentary little finger removed some years ago. X-ray film shows a rudimentary accessory third phalanx interposed between the middle and ring fingers (fig. 2).

Lower limbs : The left foot exhibits six well-formed toes and no webbing. The right foot is normal and has five toes. X-ray film of left foot : little toe presents two terminal phalanges, two middle phalanges and two heads to a common metatarso-

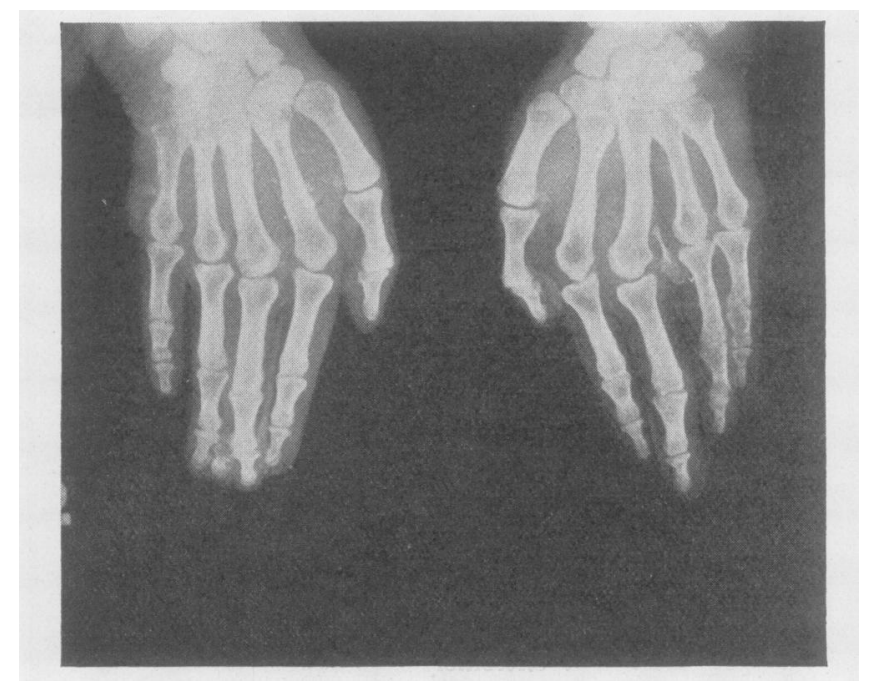

Fig. 2.

phalangeal bone (fig. 3). The legs are short and fat. Knee-jerks poor on both sides ; flexor plantar responses.

Blood count : R.B.C., 4,720,000 per c.mm.; W.B.C., 7,500 per c.mm. Differential count : polymorphs, 46.5 per cent. ; lymphocytes, 51.5 per cent. ; monocytes, 1 per cent. ; eosinophils, 1 per cent.

Sugar Tolerance Tests :

$\begin{array}{cc}\text { mg. per } 100 \mathrm{c.cm} . & \text { Time in hours } \\ 116 & 0 \\ 124 & 0 \cdot 5 \\ 145 & 1 \\ 162 & 1 \cdot 5 \\ 149 & 2\end{array}$

Calcium serum : $14.5 \mathrm{mg}$. per 100 c.cm. Serum phosphate : $3.15 \mathrm{mg}$. per 100 c.cm. Blood Wassermann : negative.

X-ray photograph of skull (fig. 4) : Outer table appears thickened and dorsum sellæ enlarged. Urine : s.g. 1020 : no albumen or sugar. 


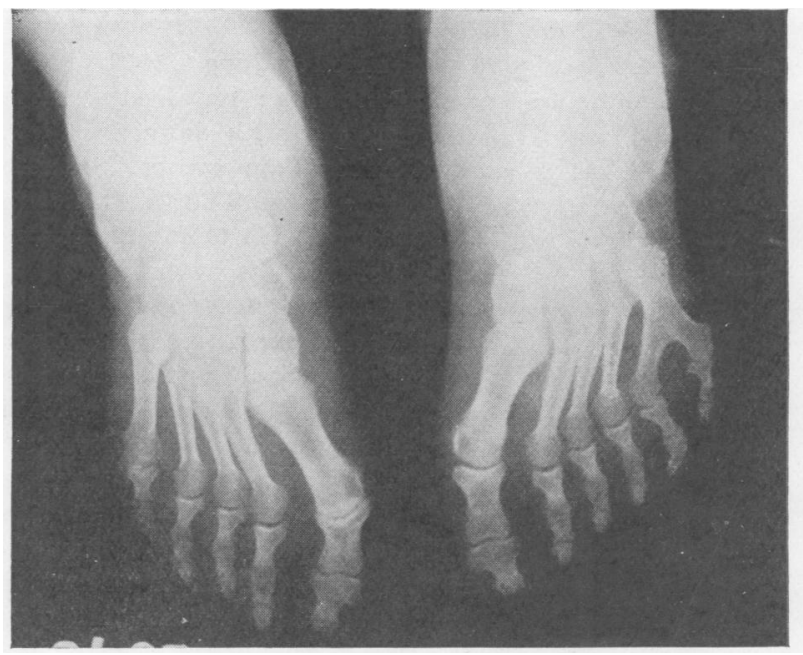

FIG. 3.

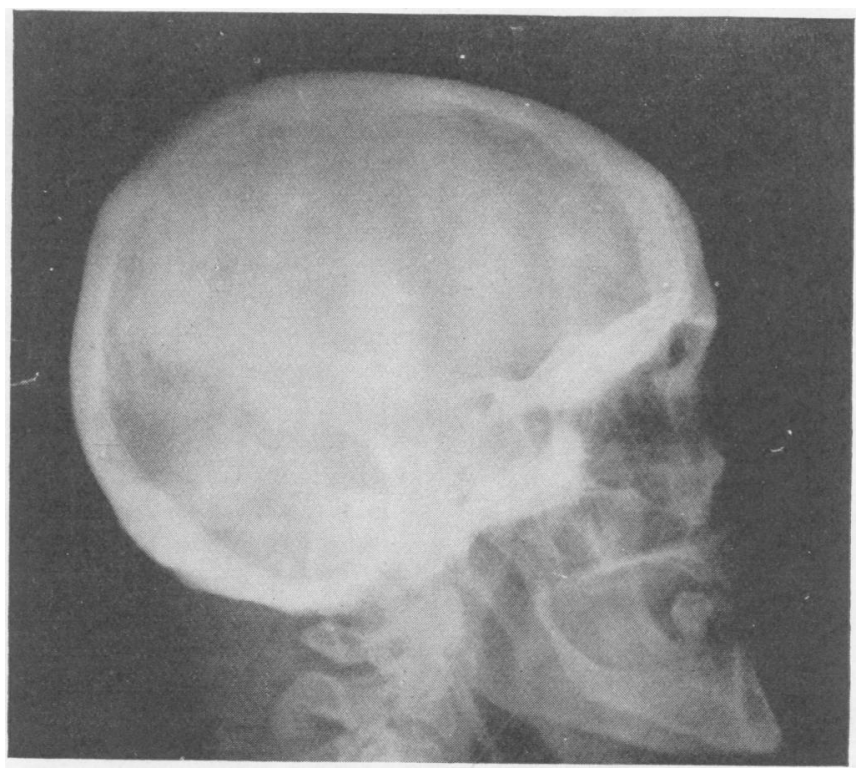

FIg. 4. 
Mental Condition.-Patient is an imbecile : simple and childish in manner; emotional ; speaks to herself; conversant with some objects by means of touch. Disorientated : remains all day in a wheel chair.

Case 1I.-L. P., female, age 72. Admitted on June 4, 1892. At that time patient was subject to moods of depression and irritability : remained seated in a chair nearly all day with downcast eyes and a stupid imbecile appearance. She refused to respond

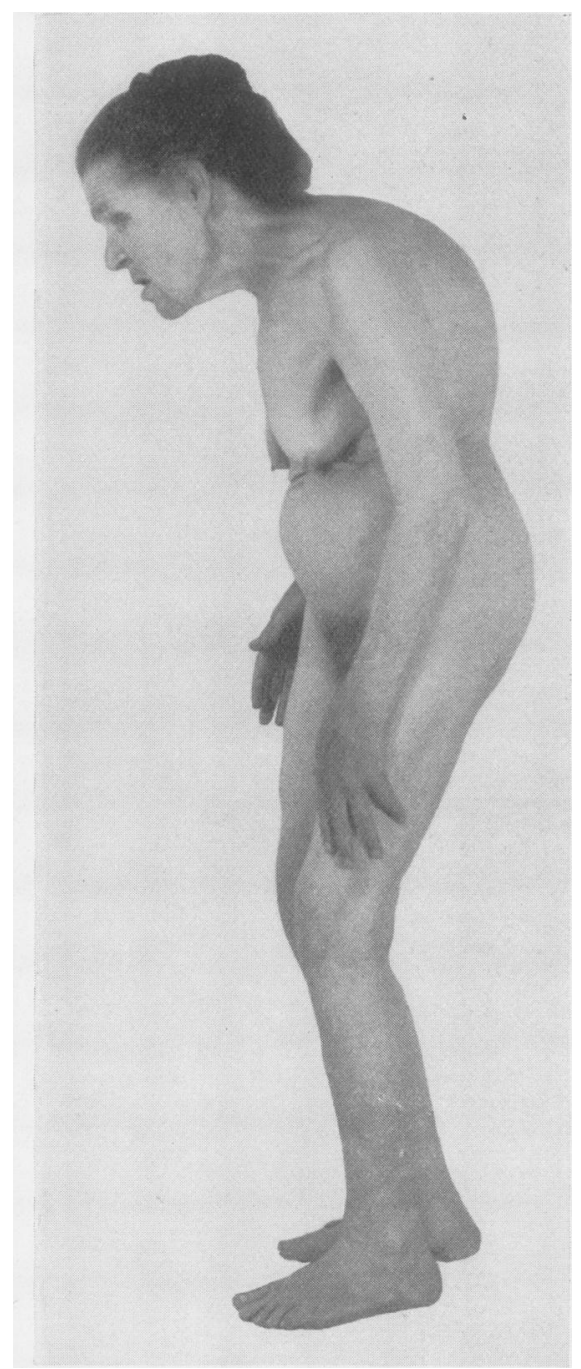

FIG. 5. to any questions and was negligent of her person. No family history was obtained in her case.

Present Appearance. - Patient has a vacant expression and appears short owing to a marked kyphosis of the spine. Present height $4 \mathrm{ft}$. 6 in. The features are rather heavy and of acromegaloid type (fig. 5). Tongue moist, clean, tremulous ; no upper teeth ; lower ones present, discoloured ; gums do not show any evidence of pyorrhœa. Weight (1934) 7 st. $11 \mathrm{lb}$. Circumference of head 23 in. There is no absence of hair on scalp or pubes.

Pulse regular: arterial wall palpable. Heart : first sound at mitral area replaced by a blowing systolic murmur heard at all areas. B.P. 150/130. Chest rachitic, emphysematous ; numerous rhonchi accompany the breath sounds. There is a marked kyphosis of the upper part of the spine and a lower lumbar lordosis. Abdomen lax ; no splenic or hepatic enlargement. There is no body or limb obesity.

Eyes : Vision dim and objects held very closely just perceptible. Pupils equal, circular and react to light. Definite nystagmus and lens opacities present. Dises difficult to see; irregular pigmentation scattered over both retinæ.

Upper limbs : Hands present no bony abnormalities : they are chilled and cyanotic. Lower limbs : Cyanotic appearance : right foot has a supernumerary little toe webbed to fifth toe (fig. 6). X-ray film : Little toe has two independent terminal phalanges and a bifid second phalanx attached to a single metatarsophalangeal bone. Left foot, five toes. X-ray of skull shows it has a thickened outline recalling Paget's disease. Dorsum sellæ appears enlarged. Knee-jerks brisk and equal. Flexor plantar response right side; left doubtful. Urine : s.g. 1018 : no albumen or sugar ; deposit of leucocytes, a few non-motile bacilli, and triple phosphates.

Blood count : R.B.C., 4,030,000 per c.mm. ; W.B.C., 8,600 per c.mm. Differential count : polymorphs, 56 per cent. ; immature, 2 per cent. ; lymphocytes, 34 per cent. ; eosinophils, 2.5 per cent. ; monocytes, 4.5 per cent. 
Blood sugar.-Resting, $93 \mathrm{mg}$. per 100 c.cm.

$\begin{array}{lll}\frac{1}{2} & \text { hour } & 169 \\ 1 & 242 \\ 1 \frac{1}{2} & 154 \\ 2 & 98\end{array}$

Calcium serum : $12.00 \mathrm{mg}$. per $100 \mathrm{c.cm}$. Serum phosphate : 2.76 mg. per 100 c.cm. Blood Wassermann : negative.

Present mental state : an imbecile ; pleasant disposition; replies to questions ; sits in a chair all day with her head buried in her chest.

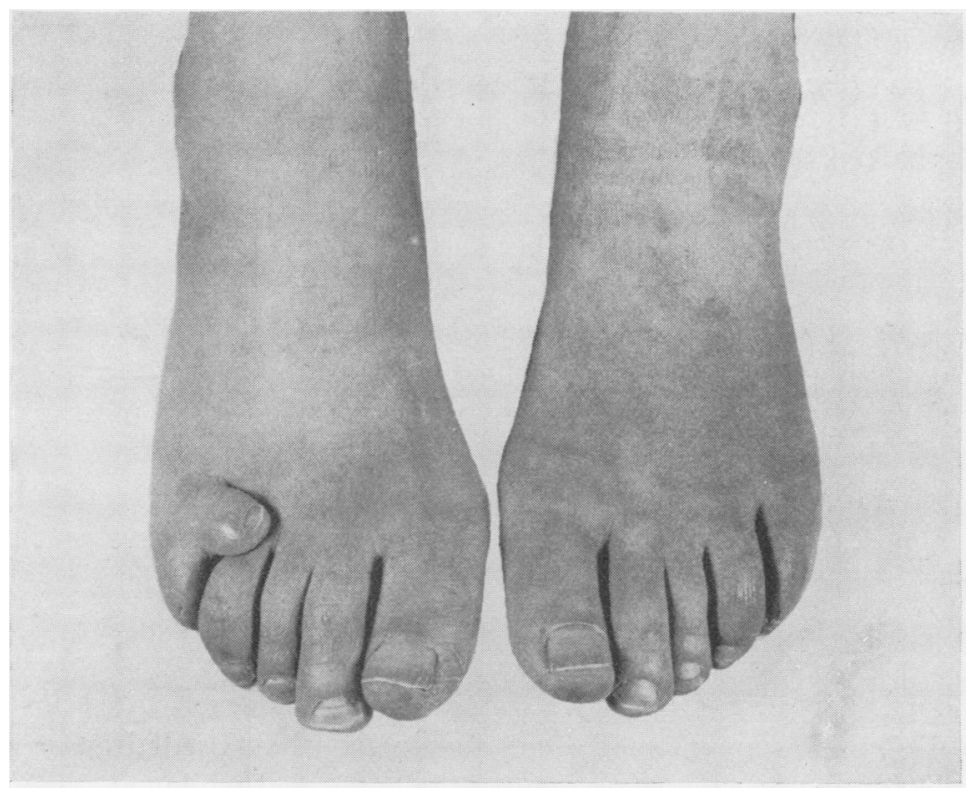

Fig. 6 .

\section{GOMMENT}

The complete Laurence-Moon-Biedl syndrome is characterized by adiposity, atypical retinitis pigmentosa, mental deficiency, polydactylism or syndactylism, dystrophia adiposogenitalis and a familial occurrence. All these features may be present, or a group of three or four signs may constitute the syndrome ; but only a few cases have been recorded without the ' cardinal' signs, viz. retinitis pigmentosa and polydactylism. In the first case here described five of the above-mentioned signs are present, and only the familial occurrence is lacking ; in the second, retinitis pigmentosa, mental deficiency and polydactylism are in evidence.

In 1866 Laurence and Moon ${ }^{1}$ reported four cases in a family of eight children and since then 77 additional cases have been recorded. In 1914 Bartolotti ${ }^{2}$ described a single case, also Bardet ${ }^{3}$ in 1920.

In 1922 Biedl $^{4}$ and in 1924 Raab ${ }^{5}$ reported another family of six living 
boys and girls of 'healthy parents, two of whom (brother and sister) showed typical retinitis pigmentosa, adiposity, genital dystrophy, polydactylism and mental deficiency. Two others in the family who died in infancy showed polydactylism.

In 1925 Solis Cohn and Weiss ${ }^{6}$ and similarly Ricaldoni and Isola ${ }^{7}$ in 1928 reported four children affected in a family of eight. The syndrome occurred in one half of the offspring of families reported by Madigan and Moore, ${ }^{8}$ Rosenstein, ${ }^{9}$ Zondek, ${ }^{10}$ Beck, ${ }^{11}$ McKinney, ${ }^{12}$ Ornsteen, ${ }^{13}$ McCrae and Weiss, ${ }^{14}$ and in one-third of the offspring in the families of Decyon, ${ }^{15}$ Grossman, ${ }^{16}$ Rozabal-Farnes, ${ }^{17}$ and Bing ${ }^{18}$; and in all the children in families reported by Kruckmann, ${ }^{19}$ Mayer and Bernhardt. ${ }^{20}$ In 1931 a case was reported by G. Griffiths. ${ }^{21}$ Of particular interest is the report of Hain ${ }^{22}$ of a group of peculiar developmental anomalies in the albino rat having some resemblance to those found in the Laurence-Moon-Biedl syndrome in man. These consisted of microphthalmia, lens opacity and blindness, while in families related to these rats other peculiarities such as skull deformities and genital malformations presented themselves.

In a series of 10 families described in the literature, 27 children were affected. In this group polydactylism or syndactylism was almost invariably present, the extra fingers or toes being rudimentary and appearing on the side of the normal fingers or toes; obesity and hypogenitalism of the Fröhlich type also occurred. Visual defects were constant; nystagmus was frequent, strabismus and optic atrophy occasional ; irregular retinal pigmentation was present in all cases. Mental development was retarded in every instance ; $\mathrm{X}$-ray pictures of the skull showed the sella smaller than normal, occasionally flattened and irregular in contour. In adult cases, however, the sella is large and regular, and has an unusually high dorsum (to which Biedl drew attention). In the two cases described here the skull is thickened while the dorsum sella appears enlarged.

Although several members of the same family may be affected, there are no records of the occurrence of the syndrome in their ancestral relations. Consanguinity has been noted in two cases. The sexes appear to be equally affected. The blood morphology does not exhibit any unusual features. Serum calcium in the two cases now reported appears to be raised. Though the association of acromegaly with the syndrome has not been hitherto described, the possibility of the coexistence of the two conditions is suggested by Case II. The patient has an acromegalic face, maxillary prognathism, marked kyphosis and lumbar lordosis, but the upper and lower limbs are not unduly large. There is no marked increase in sugar tolerance.

Several explanations for the syndrome have been suggested. By some the skeletal malformations are attributed to increased amniotic pressure, the syndrome resembling in its ætiology the congenital defects found in achondroplasia, mongolian idiocy, cleidocranial dysostosis and congenital club foot. Raab has suggested internal hydrocephalus as a cause both of the skeletal 
deformities and the inborn tendency to retinal changes, which usually develop in childhood. Biedl considers the disease of cerebral rather than hypophyseal origin and mentions structural changes in the sella as having ætiological significance. The presence of dystrophia adiposogenitalis and reports of improvement with pituitary therapy have naturally led to the assumption that the hypophysis is implicated. Bardet considers that the lesion affects both lobes of the hypophysis during embryonic and fotal development; but sugar tolerance tests do not indicate persistent signs of pituitary disease. Improvement has been reported in two instances by administration of thyroid and pituitary : DeCyon reported a response to hypophyseal extract. In one of Biedl's cases treated with thyroid and pituitary vision improved, the menses were reestablished and loss of weight to the extent of $13 \mathrm{lb}$. occurred. Others have failed to obtain any results by these measures.

In the light of the histories reported here it seems fair to conclude that the syndrome is non-progressive and that its victims may reach a comparatively advanced age.

I wish to thank Dr. R. M. Stewart, Superintendent of the Leavesden Mental Hospital, for permission to record these cases.

\section{REFERENCES}

1 LaURence and Moon, Ophthalm. Rev., 1866, 2, 32.

2 Bartolotti, Nouv. Icon. de la Salpêt., 1914-15, 27, 11.

3 Bardet, G., These de Paris, 1920.

4 Biedl, A., Deuts. med. Woch., 1922, 48, 1630.

5 RAAB, W., Arch.f. inn. Med., 1924, 7, 443.

- Solis Cohn, S., and Weiss, E., Amer. J. Med. Sc., 1925, 169, 489.

7 Ricaldoni, M., and Isola, A., Soc. méd. hóp. Paris, 1928, 52, 1131.

8 Madigan, J. J., and Moone, J. V., Jour. Amer. Med. Assoc., 1918, 70, 669.

- Rosenstein, Klin. Monatsbl. f. Augenh., 1922, 68, 204.

10 ZoNDEK, H., Die Krankheiten der endokrinen Drüsen, 1926.

11 BECK, H., Endocrinology, 1929.

12 MCKinney, J. M., Jour. Nerv. Ment. Dis., 1931, 74, 50.

13 Ornsteen, A., Amer. J. Med. Sc., 1932, 183, 256.

14 McCrae, I., and Weiss, E., Med. Clin. North America, 1931, 14, 825.

15 DeCyon, Bull. acad. de méd. Paris, 1928, 40, 444.

16 Grossman, Wien. med. Woch., 1908, 58, 742.

17 Rozabal-Farnes, Rev. Clin. de Madrid, 1913, 9, 401.

18 Bing, R., Norsk mag. laeg., 1931, $92,933$.

19 Kruckmann Mayer, Deuts. med. Woch., 1908, 34, 574.

20 Bernhardt, H., and Mayer, Zeits. f. Klin. Med., 1928, 107, 488.

21 Griffiths, G. M., Jour. Neurol. and Psychopathol., 1931, $12,53$.

22 HaIN, A. M., Nature, 1933, 711. 